\title{
Perspectiva da formação de gestores escolares na MODALIDADE A DISTÂNCIA E POTENCIALIDADES PARA O TRABALHO PEDAGÓGICO ESCOLAR
}

\author{
Perspective of the training of school managers in the distance mode and \\ potentialities for school educational work
}

BARBOSA, José Márcio Silva ${ }^{1}$ ARRUDA, Eucidio Pimenta²

\section{Resumo}

Este artigo tem como objetivo problematizar a importância da formação continuada para gestores escolares da educação básica como elemento para a melhoria da qualidade da educação pública brasileira. Defende ainda a ampliação da educação a distância $(\mathrm{EaD})$ como possibilidade de amplificar a formação de gestores escolares para atenderem as demandas crescentes da educação pública. Este trabalho parte de discussões teóricas que consubstanciam as análises desenvolvidas. De maneira geral, as análises resultam na compreensão de que a preparação atual dos gestores ainda não é suficiente para superar os aspectos que têm impacto nos resultados pedagógicos e educacionais - estilo de gestão e de liderança, questões pessoais, experiências vividas, recursos físicos e materiais - e as políticas que têm oportunizado cursos de formação inicial e continuada para gestores de escolas.

Palavras-chave: Formação de gestores escolares. Educação a distância. Trabalho pedagógico escolar.

\section{ABstract}

This article aims to problematize the importance of continuing education for school administrators of basic education as an element for improving the quality of Brazilian public education. It also advocates the extension of distance education (EAD) as an opportunity to amplify the training of school administrators to meet the growing demands of public education. This work is based on theoretical discussions that substantiate the analyzes developed. In general, the analysis results in the understanding that the current preparation of managers is not enough to overcome aspects that have an impact on pedagogical and educational results - management style and leadership, personal issues, lived experiences, physical and material resources - and policies that have provided initial and continuing training courses for school managers.

Keywords: Training of school managers. Distance education. School pedagogical work.

\footnotetext{
${ }^{1}$ Doutorando em Educação pela Universidade Federal de Minas Gerais. Mestre em Educação pela Universidade Federal de Viçosa, Graduação em Ciências Econômicas pela Universidade Federal de Viçosa e Licenciado em Ciências Sociais pela Universidade Metropolitana de Santos (UNIMES). Profissão: professor de ensino superior. Ocupação atual: estudante e pesquisador. E-mail: <jmarciosb@yahoo.com.br>.

${ }^{2}$ Professor e pesquisador no Programa de Pós-Graduação em Educação: Conhecimento e Inclusão Social - UFMG. Pós-Doutor em Ciência, Tecnologia e Sociedade pela UFSCAR, Doutor em Educação pela UFMG. E-mail: <eucidio@ufmg.br>.
} 


\section{INTRODUÇÃO}

Este artigo aborda um estudo teórico sobre a formação de gestores escolares realizada em curso de educação a distância e seu impacto sobre o trabalho pedagógico escolar. Parte de reflexões que ainda estamos realizando no âmbito da pesquisa científica, em curso de doutoramento do autor, na qual se investiga a relação entre as temáticas anteriormente apresentadas.

Nesse sentido, o estudo, inicialmente, tem sido de caráter exploratório, na busca por uma revisão de literatura sobre os temas propostos, cujo propósito é levantar, nos estudos consultados, pistas que acenam para os desafios que são postos para a transformação da realidade escolar a partir do que tem sido ofertado pelo Programa Nacional Escola de Gestores da Educação Básica.

A formação continuada nos últimos anos ganha destaque nas pesquisas e estudos em diversas partes do mundo. Tema que envolve perspectivas e desafios contemporâneos tem sido colocado à educação como cenário de profundas mudanças na sociedade e no trabalho dos profissionais envolvidos. Desse modo, tem trazido à tona o trabalho pedagógico escolar, que ainda permanece em aberto, particularmente, no que diz respeito às reflexões teóricas e práticas que estão na base do trabalho e da competência profissional dos professores.

O Programa Nacional Escola de Gestores da Educação Básica Pública tem como objetivo geral a formação de diretores e vice-diretores em exercício na escola pública, em nível de especialização (Lato Sensu), gestores educacionais efetivos das escolas públicas da educação básica, incluídos aqueles de educação de jovens e adultos, de educação especial e de educação profissional, além de contribuir com a qualificação do gestor escolar na perspectiva da gestão democrática e da efetivação do direito à educação escolar com qualidade social.

A exigência de novas propostas pedagógicas conduz às condições e às experiências vividas pelos gestores, levando-se em conta os seus próprios referenciais teóricos e práticos. Se por um lado devem assumir, na possibilidade inerente à gestão escolar, o desenvolvimento do aluno, por outro, subentende-se que eles possam dar conta do conhecimento teórico constante e renovado, privilegiando-se sua experiência e sua materialização no âmbito escolar.

Não resta dúvida de que a realização do curso na modalidade a distância tem propiciado uma oportunidade ímpar aos profissionais da educação básica para realização de curso em nível de pós-graduação, supondo uma mediação pedagógica e tecnológica necessária ao processo formativo do cidadão. Apesar da importância da preparação formativa para o exercício docente no âmbito escolar, entendemos ser importante subtrair uma riqueza de informações e de responder por suas ações. Há a necessidade de investigar, no âmbito escolar, para o que tem contribuído na modificação do trabalho pedagógico escolar somado à capacitação adquirida.

Não é que se espere que a comunidade ofereça soluções pedagógicas, mas é no nível de decisão mais amplo que certamente a sua contribuição é de todo imprescindível. Em decorrência de tal situação, entendemos que a formação continuada estimule a busca constante por aprimoramento profissional, tendo em vista que o curso, em nível Lato Sensu, revela de forma explícita como vem sendo tratada a questão da formação continuada de gestores escolares pelo sistema de ensino a distância, considerando-se especialmente a utilização de conhecimento e o aprimoramento em âmbito escolar. 
Além disso, consideramos, também, que a formação continuada é condição importante para a releitura das experiências e das aprendizagens obtidas. A aposta nas possibilidades de produzir múltiplos olhares e na fusão do que se pensa e se faz com o processo educativo se torna uma exigência profissional ao enfatizar a reflexão sobre a própria prática. Respaldado nos conteúdos curriculares no ambiente virtual, todo gestor deve ter como base a oportunidade de observar e refletir sobre sua prática, seu contexto e condições de trabalho, dialogadas e teorizadas, dando legitimidade a esse trabalho. Insistimos no fato de que nenhum dos sujeitos envolvidos no processo pedagógico pode desconhecer o modo como sua formação profissional e a prática escolar são aspectos indissociáveis.

Ao defender que a formação em serviço pode ser uma ferramenta importante para mobilizar experiências inovadoras, coloca-se como verdade a ideologização de que esses cursos levariam a modificações qualitativas no fazer pedagógico da escola. Desse modo, o gestor escolar não pode ser relegado ao segundo plano, sem se levar em conta o questionamento, o engajamento e a resistência desses profissionais para a restauração do direito de uma escola de qualidade. Nesse movimento, não se pode abrir mão da realidade, de modo que eles construam sua própria realidade, estabelecendo relações dialéticas com as necessidades educacionais, o que não seria constituída sem conflitos e contradições.

Não temos a intenção de apontar soluções para as superações das limitações com que hoje nos deparamos para delimitar o trabalho pedagógico escolar de modo qualitativo, mas demarcar na trilha de investigação a maneira como o trabalho pedagógico escolar está inserido no âmbito das políticas de formação e de que maneira o mesmo possa ser pensado na prática de gestão escolar. É esse objetivo de recrutar futuras modificações no fazer pedagógico da escola que constitui o desafio no tempo presente.

\section{CONTEXTUALIZAÇÃo DA FORMAÇÃo CONTINUADA DE GESTORES ESCOLARES E EDUCAÇÃO A DISTÂNCIA}

No Brasil há boas e interessantes experiências no campo da formação continuada. Nesta busca, em 2005, nasceu o Programa Nacional Escola de Gestores da Educação Básica, que vem sendo implementado em regime de colaboração firmado entre o Ministério da Educação (MEC) e os sistemas estaduais e municipais de ensino no país. Este programa vem abrindo espaços para construir um processo de formação de gestores escolares que contemple a concepção do direito à educação escolar e perceba a escola na perspectiva da inclusão social, da emancipação humana, na descentralização e na maior autonomia para a escola; no sentido de trabalhar na perspectiva da mudança, viabilizando estratégias que possibilitem a participação dos atores escolares nas instâncias de planejamento, execução e avaliação para a construção respaldada em suas experiências de uma "nova escola". Seu objetivo geral é formar, em nível de especialização (Lato Sensu), gestores educacionais em exercício nas escolas públicas da educação básica, incluídos aqueles da educação de jovens e adultos, da educação especial e da educação profissional, bem como contribuir com a qualificação do gestor escolar na perspectiva da gestão democrática e da efetivação do direito à educação escolar com qualidade social (BRASIL, MEC, 2005).

Propiciar um movimento de reflexão teórico e prático entre conteúdos e atividades propostas no ambiente do curso de pós-graduação com a realidade cotidiana das escolas públicas tem sido o ideal da formação profissional. Essas propostas são 
utilizadas pelo Ministério da Educação para atualizar a prática educacional, visando a trazer os profissionais para os anseios educacionais contemporâneos e para a melhoria da qualidade da educação no país.

A formação que se proporciona é pautada no estudo de temas como política educacional, gestão democrática, cultura e currículo, processos de ensinoaprendizagem, processos comunicacionais, planejamento e avaliação que se articulam na discussão sobre a organização do trabalho pedagógico, foco da intervenção do gestor escolar, enquanto integrante da equipe gestora da escola. $O$ desafio no tempo presente é a capacitação para saber usá-las e a destreza que se adquire com a prática.

Há décadas se discute qual seria a formação ideal ou necessária do profissional da educação do ensino básico por meio de uma mudança qualitativa na escola. Para a formação desse educador, a implementação de políticas e programas formativos, particularmente em gestão, ganha a dianteira na realização de programas de capacitação para os profissionais de educação em exercício. A Lei de Diretrizes e Bases da Educação Nacional (LDBEN) de no 9.394 de 1996 em seu Título VI, trata dos profissionais da educação, sendo que seu art. 67 assegura a promoção de formação continuada para professores da rede pública, por parte dos respectivos sistemas de ensino, afirmando que os sistemas de ensino promoverão a valorização dos profissionais da educação, assegurando-lhes, inclusive nos termos dos estatutos e dos planos de carreira do magistério público [...] o aperfeiçoamento profissional continuado [...] (BRASIL, MEC, 1996, p. 23).

Podemos, ainda, relatar que a formação continuada de gestores escolares, por intermédio de cursos a distância, implementada por órgãos oficiais é uma realidade. A educação a distância está a serviço do desenvolvimento e da aprendizagem dos alunos, favorecendo, de forma efetiva, a democratização do ensino, tornando-se o instrumento necessário à sua formação de modo acessível a todos os que dele participam. A criação da Universidade Aberta do Brasil (UAB), pelo Decreto n. 5.800 de 2006, institucionaliza os programas de formação de professores a distância como política de formação de professores, com o objetivo de expandir e interiorizar a oferta de cursos e programas de educação superior públicos, a distância, oferecendo, prioritariamente, cursos de licenciatura e de formação inicial e continuada de professores da educação básica, cursos superiores para capacitação de dirigentes, gestores e trabalhadores em educação básica (BRASIL, MEC, 2006).

Entretanto, o fulcro do problema, que ainda permanece nas discussões dos cursos de formação continuada no país, não está suficientemente estudado. Mas há vestígios na literatura especializada sobre a concepção idealizada da realização existente entre o que poderia manifestar ou ocorrer no espaço escolar e as procedências de atuações do profissional da educação em relação ao processo formativo proposto inicialmente.

Entende-se que a situação problemática da educação brasileira é atribuída à inadequada formação profissional, com base nos aspectos pedagógicos na escola, na carência de postura investigativa da formação docente e na insuficiência da prática do processo formativo, além da formação disciplinar, levando à visão de um mundo fragmentado, incapaz de dar conta da complexidade do trabalho docente (SEVERINO, 2004). Sustenta esse posicionamento a compreensão de que todos os problemas relacionados com a educação são problemas da coletividade, não sendo exclusivamente do governo. No entanto, dessa ampla e continuada discussão, não têm emergido propostas que ultrapassem o nível de recomendações concretas sobre a 
necessidade de "sólida formação dos educadores", da "integração de teoria e prática", da "interdisciplinaridade" etc. (AZANHA, 2004).

Em decorrência da situação exposta, compreendemos que a formação de gestores escolares passa a ser uma necessidade e um desafio para o sistema de ensino. Essa responsabilidade se torna mais marcante quando se evidencia a necessidade de formação contínua, complementar à formação inicial, como condição para acentuar o processo de profissionalização de gestores, de modo que estes enfrentem os novos desafios a que estão sujeitas as escolas e os sistemas de ensino.

Não se pode deixar de considerar que o Programa Nacional Escola de Gestores da Educação Básica passa a fundamentar e orientar práticas de ações que devem ocorrer em situações escolares concretas. Como disse Gatti (2008), a educação continuada foi colocada como aprofundamento e avanço nas formações dos profissionais em resposta a problemas característicos de nosso sistema educacional.

Um componente importante da problemática na implantação dos cursos de formação de professores pelas novas diretrizes certamente se refere à dificuldade em assegurar a necessária articulação entre o processo formador considerado pelas instituições de ensino superior e o trabalho exercido nas escolas, exigido pelo programa atual. Descrever esse quadro só é possível na instituição escolar, que deve ser o centro de preocupações teóricas e de atividades práticas.

É preciso que sejam superadas, com políticas de gestão, limitações comumente detectadas em relação ao uso de formação profissional na área de educação. Um fator limitador desse investimento seria, na visão de Lück (2000), o baixo retorno de programa de capacitação de profissionais da educação em termos de transformação da realidade, levando ao distanciamento entre teoria e prática, o que se explica justamente pelo caráter teorizante, conteudista e livresco dos programas de formação, sem o cuidado de evidenciar, por meio de situações simuladas, por dramatizações ou estudos de casos e outros exercícios, a aplicação e a expressão na realidade das concepções teóricas tratadas. Para essa mesma autora, os programas de capacitação de profissionais da educação em termos de transformação da realidade, ou seja, em relação à prática docente, não podem ser visto como uma simples transmissão de conhecimentos já produzidos, mas como uma oportunidade de produzir e transformar saberes próprios dos professores, que, refletindo e investigando a própria prática, são os agentes transformadores da escola.

Em certa medida, os objetivos e as expectativas do programa tendem a criar um perfil profissional de gestores escolares que busquem modelar sua prática com compreensões pedagógicas da gestão escolar de maneira integrada, para que, por meio de fatores internos e externos, possam refletir e desenvolver práticas educativas inovadoras no ambiente escolar, bem como possibilitar oportunidades para ampliação da capacidade de analisar e resolver problemas, elaborar e desenvolver projetos e atividades na área de gestão para garantir os processos socioeducacionais nos estabelecimentos de ensino.

$\mathrm{Na}$ raiz dessas possibilidades, cabe lembrar a ideia de Gatti (2008) ao constatar que poucos questionamentos nos cursos de formação continuada no país têm sido feitos por parte dos cursistas, tendo em vista estarem habituados a apresentar uma postura passiva diante de cursos de capacitação ou atualização e nem sempre uma postura de aprofundamento ou ampliação de conhecimentos adquiridos. Contudo, esses questionamentos não parecem se referir a situações reais e concretas e, por isso, 
deixam de interessar aos gestores como algo referente à sua prática. Lück (2000) havia, de fato, identificado que o distanciamento ocorre, no entanto, quando os cursos focalizam conhecimentos, centram-se em conteúdos formais, deixando de lado os componentes necessários para o desempenho profissional, que são as habilidades - 0 saber fazer - e as atitudes - o predispor-se a fazer. Por conseguinte, cursos assim organizados são orientados mais para a cognição e menos para a competência.

O fato concreto de que teremos um contingente cada vez maior de professores que fazem a opção por uma formação vinculada a um curso de pós-graduação lato sensu, algo que não é descontextualizado da realidade da educação básica, configura-se como uma constante e parece que veio para ficar, impondo às Universidades e em especial aos Programas de Pós-Graduação de todo o Brasil o debate acerca do papel social que cada gestor escolar deve exercer em favor da melhoria das condições de trabalho e da sua valorização profissional (CANDEIAS, 2013).

Algumas propostas que emergem desse enfoque sobre a preparação atual dos gestores ainda não são suficientes para superar os aspectos que têm impacto nos resultados pedagógicos e educacionais - por exemplo, estilo de gestão e de liderança, questões pessoais, experiências vividas, recursos físicos e materiais - e nas políticas que têm oportunizado cursos de formação inicial e continuada para gestores escolares. Para Gatti (2008), muitas das iniciativas públicas de formação continuada no setor educacional adquiriram programas compensatórios e não propriamente de atualização e aprofundamento em avanços de conhecimento, tendo estes programas a finalidade de suprir aspectos da má formação anterior, alterando o propósito inicial dessa educação, que seria o aprimoramento de profissionais nos avanços, renovações e inovações de suas áreas, dando sustentação à sua criatividade pessoal e à de grupos profissionais.

As diretrizes propostas pelo programa Escola de Gestores/MEC têm em suas metas a gestão democrática como foco a ser alcançado, subsistindo esse foco pela compreensão de que a ampliação da democracia no ambiente escolar é o principal objetivo a ser perseguido. Essa democratização envolve também, evidentemente, a adoção de procedimentos organizacionais regionalmente distintos, em observância à diversidade nacional. Por fim, merece destaque a preocupação com o desenvolvimento da capacidade para analisar e refletir diante de situações problema, na busca por resoluções possíveis em seu dia a dia (PEREIRA, 2011, p. 5 apud SOUZA \& TEIXEIRA, 2010).

Estes procedimentos se traduzem na inovação de processos pedagógicos ao oportunizar aos professores e aos gestores o acesso a novos conhecimentos de ensino e criação de novas metodologias de aprendizagem e de gestão. Com isso, notamos que os olhares e vozes dos próprios gestores exploram o desenvolvimento de um espírito crítico relativo à sua atuação mais geral acerca da importância do exercício profissional, gerando sempre o compartilhamento e o diálogo, de modo que o ser, o valer e o refletir sejam vividos como elementos integradores nas diferentes circunstâncias no cotidiano escolar.

Segundo essa concepção, a formação de professores, ao se relacionar diretamente com o funcionamento cotidiano das escolas, termina por dialogar com a possibilidade da construção de uma realidade mais justa, democrática e humana, interferindo na condução das sociedades contemporâneas (CANDEIAS, 2013). Esta formação visa a adequar a escola a um papel fundamental no processo de democratização, uma vez 
que "cabe às instituições formadoras relevantes papéis no estabelecimento de componentes curriculares teórico-práticos capazes de suscitar nos futuros gestores a problemática da gestão democrática" (CURY, 2002). A relevância dessa abertura legal está associada ao entendimento de que os cursos de formação inicial ou continuada precisam ter alicerces na prática, caso contrário, não conseguem fornecer instrumentos para uma atuação profissional efetiva nem propiciam mudanças de percepção dos sujeitos, visto que boa parte das práticas escolares é rotineira e, portanto, não se transforma num passe de mágica, sendo fruto de um processo (TEIXEIRA, 2011, p. 67 apud CARNEIRO, 2006, p. 59).

Um aspecto presente na visão de Freitas (2009) é que um dos problemas com os quais os professores comumente se defrontam está relacionado à dificuldade em transformar o conhecimento adquirido ao longo da formação em uma concepção técnica de ensino, tendo em vista que a maioria dos cursos de formação na modalidade a distância, no Brasil, contraria todos os requisitos necessários, sendo uma forma de aligeirar e baratear a formação. $\mathrm{E}$, por isso mesmo, esses cursos tendem a ser pensados mais como uma política compensatória que visa a suprir a ausência de oferta de cursos regulares a uma determinada clientela, sendo dirigidos a segmentos populacionais historicamente já afastados da rede pública de educação superior, consequentemente, ainda não existindo um corpo consistente de pesquisa e experimentação que permita corroborar as vantagens comparativas em termos da educação a distância, nem sua eficácia no âmbito da educação básica (TORRES, 2001).

Ainda que algumas alternativas de acompanhamento e avaliação em curso no País estabeleçam indicações qualitativas, será necessário buscar algumas informações com gestores escolares, sujeitos partícipes do referido curso, tendo em vista que as questões que poderão ficar em evidência são: o que se manifesta no contexto interno da escola e na atuação do profissional egresso de uma Universidade Federal para o aperfeiçoamento do trabalho pedagógico escolar; e em que medida a formação obtida vem induzindo mudanças qualitativas na escola, seja na articulação, na reflexão profissional e no desenvolvimento de práticas escolares.

As respostas a essas perguntas são muitas e estão longe de ser unânimes, mas parecem sinalizar uma tendência a se agruparem em torno da ideia de reflexão (grifo da autora) constante sobre a prática pedagógica propícia à integração dos meios técnicos de comunicação e de informática aos processos educacionais, uma vez que a reflexão sobre a própria prática "conduz necessariamente à criação de um conhecimento específico ligado à ação, que pode ser adquirido pelo contato com a prática, pois se trata de um conhecimento tácito, pessoal e não sistemático" (BELLONI, 1998, p. 6 apud GARCIA, 1992, p. 59-60).

Essa tarefa consiste principalmente na definição de problemas prioritários da escola vinculada aos objetivos articulados ao domínio de conhecimentos, tendo, possivelmente, melhores condições de ser atingidos, isto é, de atender ao proposto pelo programa no que se refere ao objetivo de ampliar a condição de reflexão, ação e mudanças nas questões educacionais no âmbito da gestão escolar, por meio da instrumentação teórica. Espera-se que as iniciativas governamentais de formação de gestores escolares sejam pautadas na concepção da gestão democrática, no exercício da autonomia, na emancipação humana, privilegiando a reflexão sobre as trajetórias 
individuais e coletivas, considerando que os gestores podem ser protagonistas de sua prática e do seu próprio processo de formação.

Essas iniciativas fomentadas e avaliadas pelo Ministério da Educação visam a obter novas práticas educacionais democráticas através da gestão escolar, sendo as políticas vistas como adequadas pelo governo, por favorecerem as desejadas melhorias na qualidade da educação pública brasileira, alvo dos planos e metas do governo. No entanto, a efetivação dessas mudanças mostra que os objetivos principais destas duas iniciativas, a qualificação do dirigente escolar e a fomentação de melhorias na gestão escolar, segundo Pereira (2011), impõem a necessidade de despertar para a intencionalidade de um Programa que objetiva formar o gestor, monitorando-o e avaliando-o permanentemente por meio dos trabalhos postados na plataforma. Partindo de seus conhecimentos prévios, permeados, inicialmente, pelo senso comum, procura-se elevar seus conhecimentos ao patamar científico, estabelecendo mediações com a realidade escolar em que atua (QUEIROZ E GADELHA, 2012). Ainda a respeito dessa perspectiva, Pereira (2011), ao fazer uma análise do programa, mostra que são um conjunto de ideias trazidas pelo MEC, ao diretor de escola, que visam a criar nesses sujeitos condições para modificação de suas práticas de gestão escolar, além de aproximar esse sujeito das reais intenções das proposições políticas, dos meios de sua construção e implementação.

Essas constatações na concepção de formação do gestor indicam mais do que alcançar a interpretação compartilhada da informação a partir da sua disseminação, sendo necessário mostrar como os cursistas questionam ou utilizam o conteúdo curricular como base para a ação. Essas são questões importantes, levantadas na investigação sobre o assunto, que podem ser consideradas um caminho para uma educação inovadora, segundo uma roupagem caracterizada pela interatividade, cabendo a eles criar um posicionamento de protagonista sobre essa nova perspectiva da escola reflexiva, de formação inicial e continuada, do desenvolvimento do profissional, que ocorre durante a vida do professor, na sua interação com a sua prática, com o coletivo escolar e com o contexto organizacional no qual estão inseridos (RIVAS; PEDROSO; LEAL; CAPELINI, 2005).

O fato é que, no bojo dessas discussões, os profissionais da educação são convidados a participar de forma mais ativa da vida nas escolas, pois são eles que experimentam, no cotidiano escolar, práticas pedagógicas em seus distintos níveis e modalidades de ensino. Torna cada vez mais relevante a capacidade de recolher indícios, de atingir níveis de complexidade na interpretação de seus significados e de incorporá-los a eventos relevantes e possíveis para a construção da qualidade, da gestão democrática e participativa na escola, na condução de ações pedagógicas e administrativas, com vistas a consolidar uma ação que favoreça esses processos.

Essas modificações deverão ocorrer de forma sequencial e gradativa para que com olhar crítico e consciente sobre o que aprendeu e o que envolve a atuação concreta no cotidiano de seu trabalho pedagógico, o gestor escolar envolva todas as ações e situações que postula como necessárias e se desenvolva em um contexto marcado por profundas mudanças na vida da instituição escolar, indo em direção ao enfrentamento crítico ante os desafios do trabalho pedagógico escolar.

Com base nesses referenciais, entendemos que é fundamental uma contribuição nessa direção no que se refere à formação continuada a distância. 
A Escola de Gestores tem sido uma estrutura de formação profissional, caracterizada como modalidade à distância, bem como espaço de reflexão e debate entre os participantes que, por sua vez, têm envolvimento com a educação básica. Assim, buscamos demonstrar, nesta seção, ainda que brevemente, como a educação a distância tem sido vital para a formação docente e, em particular, aos gestores escolares da educação básica.

A educação a distância surge como um redimensionamento das transformações na configuração da sala de aula como forma de ensinar e aprender virtualmente. Os cursos em EaD vem demonstrando um potencial em democratizar a educação, bem como permitir o acesso aos profissionais da educação à qualificação e ao aprimoramento profissional.

Neste sentido, a implantação de cursos de pós-graduação na modalidade a distância em instituições de ensino superior vem se intensificando nos últimos anos no intuito de suprir a demanda dos procedimentos tradicionais de ensino-aprendizagem já consolidadas. Percebe-se que houve vultosas expansões de cursos a distância para democratizar o ensino.

O movimento inicial de EaD é de proporcionar formação regular e continuada aos professores em serviço para melhorar o seu desempenho, competência, autonomia e iniciativa nos cursos oferecidos na modalidade a distância. Dessas iniciativas, passouse a incorporar a educação a distância como forma de poder atingir, sobretudo, os professores em exercício nas escolas públicas que não possuíssem uma formação escolar condizente com as exigências para o exercício profissional da docência (GATTI, 2008, p.143).

Gatti (2005) sintetiza algumas das características e dos fatores que têm sido evidenciados como propiciadores de um nível qualitativo de alto diferencial para a formação a distância de professores. Para a autora, é mais rico o processo educativo a distância para formação de professores quando se adota uma postura sobre a aquisição de conhecimentos, tratada e concebida com a busca permanente, como reflexão vinculada às práticas sociais e pedagógicas; constituindo-se pela atividade das pessoas em seus contextos.

A relação entre educação a distância e a formação de professores pode se constituir em uma oportunidade na busca de conhecimento. E no ambiente virtual, quando teoria e prática se coadunam, permitem aprofundar didática e formalmente o entendimento e a apreensão da realidade escolar.

A avaliação do aluno legitima a tornar indispensável o processo educativo. Sua função mais evidente e reconhecida é a pedagógica, que visa, principalmente, à verificação de suas necessidades e à melhoria do processo de ensino-aprendizagem (AZZI, 2005). Para a autora, a avaliação em EaD, como em qualquer outra modalidade de ensino, apoia-se na interdependência das modalidades diagnóstica, formativa e somativa, com ênfase na sua continuidade. Nesse sentido, a matriz curricular do curso foi organizada por temáticas que se relacionam aos dois níveis de abrangência do trabalho pedagógico do profissional em questão, às quais serão desenvolvidas em Salas Ambientes Virtuais. Entendemos ser importante a discussão em torno destas, como prática pedagógica essencial à aprendizagem dos alunos. Ao contrário do ensino presencial, é por meio delas que as instituições de ensino superior oferecem condições de ensino-aprendizagem. Ou como nos mostra Mill (2012), elas oferecem as condições 
necessárias para que o conhecimento seja construído adequadamente e a formação pretendida seja possível.

Face a essas breves e preocupadas considerações, estamos convictos de que para a educação básica avançar em qualidade, que passou a ser vista como necessária, é preciso compreender como os gestores escolares adotam ou aprimoram propostas criativas e possibilidades de boa gestão escolar para exercício de um trabalho mais produtivo, mais ativo e permanente no estabelecimento de ensino. Tudo isso vem se somar ao surgimento da educação a distância como alternativa para potencializar e disponibilizar o conhecimento para um número cada vez maior de indivíduos interessados em completar ou mesmo iniciar seus estudos, visando a adaptar professores, diretores, coordenadores, ou seja, toda equipe escolar, aos processos formativos e às transformações necessárias no âmbito das políticas propostas de formação, bem como à prática profissional de que prescindem.

\section{TRABALHO PEDAGÓgICO ESCOLAR: ALGUMAS CONSTATAÇÕES}

O trabalho pedagógico escolar constitui uma prerrogativa de reflexão das especificidades locais que devem ser consideradas, devido ao grande impulso da direção à formação de professores ao longo das últimas décadas.

Há uma forte tendência em que o gestor escolar seja o agente transformador nos processos de elaboração e planejamento das políticas educacionais. Compreende-se que a prática pedagógica seja embasada nos saberes docentes, podendo, desse modo, contribuir para a melhoria qualitativa da escola. Essa preocupação se dá na perspectiva de que educadores reflexivos do desenvolvimento de sua práxis pedagógica, a partir da aquisição de novos conhecimentos, oportunidades de reflexão e debate sobre os desafios da profissão, poderão transformar as suas práticas e contribuir com a vivência de uma gestão democrática no cotidiano escolar (FELINTO; PEDREIRA, 2014).

Para compreender tal dinâmica, a abertura de espaços reflexivos precisa ser articulada de maneira que esses sejam capazes de propiciar um contínuo repensar sobre as práticas cotidianas. Consideramos que ao trilhar este caminho, o conhecimento profissional deve constituir-se a partir da vivência e das análises de práticas concretas que permitem, constantemente, o diálogo entre a experiência concreta em sala de aula e a formação teórica.

Alonso (2005) questiona a partir de quais critérios poderia avaliar se um conhecimento é válido, ou ainda, se é importante, ou se alguns se apropriaram de um determinado conceito. Sabe-se que todo o processo educativo-formativo tem por base uma relação eivada por valores e lugares sociais, significados culturais, compreensões e projetos, sobretudo projetos de vida. É nessa teia que as práticas pedagógicas são forjadas, buriladas e veiculadas.

Recentemente, tais perspectivas estão calcadas no papel do gestor escolar por ser quem toma frente na organização da gestão escolar, em prol do desenvolvimento de seus sujeitos, da comunidade escolar e dos agentes educacionais, tendo em vista que os processos educacionais envolvem o pedagógico e o administrativo. Supõe-se que essas perspectivas dão aos dirigentes escolares alguma condição real de aplicação dos conhecimentos que assimilam durante o curso; repasses a serem efetivados pelos 
gestores escolares sobre o trabalho que se pretende realizar nas diferentes formas de atuação; e ainda conduza as escolas rumo à qualidade social.

Neste sentido, o cotidiano da formação de educadores deve ser marcado por um diálogo interativo entre cultura, teoria de aprendizagem, gestão da sala de aula e da escola, atividades pedagógicas e domínio das tecnologias que facilitem o acesso à informação e à pesquisa, bem como que permita buscar uma formação de sujeitos autônomos, capazes de buscar, criar e aprender ao longo de toda a vida e de intervir no muno em que vivem (NEVES, 2005, p. 137). Estes aspectos integram a proposta de políticas de formação profissional docente inicialmente planejada pelo curso formativo. Assim, ele consolida-se como uma estratégia política de formação em serviço para os gestores de escolas e um veículo de disseminação dos conteúdos, que visa a adequar a escola a um papel fundamental no processo de democratização.

A escola deve ser o ambiente onde o gestor tenha a possibilidade de reconstruir sua prática através de uma dinâmica de trabalho. Para esta proposta o enfoque teóricometodológico do curso de pós-graduação em gestão escolar aponta um caminho a ser percorrido através de pressupostos pautados nos princípios de uma gestão democrática, na autonomia da escola e na participação da comunidade escolar visando à formação do gestor escolar para que ele possa desenvolver um trabalho de gestão pedagógica eficiente.

É preciso ir além das proposições se não acompanhadas por ações efetivas nas políticas públicas que estejam voltadas para uma perspectiva de modificações qualitativas no trabalho do gestor no âmbito escolar. Entendemos que o contínuo aperfeiçoamento do gestor enseja um novo projeto pedagógico, pois é ele que deverá servir de base para traçar novos rumos para um caminhar mais direcionado, bem como para a conquista das transformações almejadas. Todos os processos que ocorrem no espaço escolar devem ser entendidos e explicados sempre em uma perspectiva mais ampla da organização do trabalho pedagógico, tendo que requerer uma compreensão adequada da maneira como ele atua conforme o processo de sua formação, bem como das relações e dos processos que se estabelecem entre os sujeitos da escola professores, estudantes e diretores - e o conhecimento apreendido por estes durante a vida escolar.

A tarefa precípua de organizar o trabalho na escola não leva o gestor escolar como o único responsável pelas múltiplas tarefas realizadas pelos quais deverá responder, mas por ter contato com toda a equipe gestora da escola, coordenando necessidades e aspirações, rediscutindo o vínculo entre teoria-prática, entende-se que o trabalho pedagógico compreende todas as atividades teórico-práticas desenvolvidas por toda a equipe escolar no estabelecimento de ensino. Em outras palavras, a organização do trabalho pedagógico é constituído pelo Conselho de Classe, Conselho Escolar, equipe pedagógica, equipe da direção, enfim, todos aqueles que estão diretamente envolvidos com a participação na organização do trabalho pedagógico.

Para chegar à explicitação da nova organização é necessário que a escola traduza para si, especifique e detalhe avanços e problemas cruciais de forma a garantir a sustentabilidade na implementação de ações voltadas para o fortalecimento das escolas e para a melhoria do desempenho do ensino público, envolvendo, primordialmente, decisão política, ação técnica-pedagógica e gestão democrática na escola. Como resposta a essa nova perspectiva da escola reflexiva, de formação inicial e continuada, o desenvolvimento do profissional ocorre durante a vida do professor, na 
sua interação com a sua prática, com o coletivo escolar e com o contexto organizacional no qual estão inseridos (RIVAS et al., 2005). Estas preocupações estão presentes em recentes esforços teóricos no campo da formação em consonância com o referencial teórico-metodológico para a organização e orientação do trabalho escolar.

O gestor poderá incentivar e articular o desenvolvimento de ideias, de conhecimento, com a finalidade de implementar novas práticas pedagógicas que visem à melhoria e à qualidade de ensino dentro das ideais demonstradas. Pensando nessas circunstâncias essenciais, na elaboração ou atualização da proposta pedagógica, torna-se possível de as mesmas serem alcançadas por trazerem benefícios às práticas educativas de qualidade. Por estes motivos, reforçamos a ideia de que o trabalho pedagógico deve ser o objetivo a ser perseguindo por toda a escola. Não esperamos encontrar apenas uma única forma de organização no trabalho pedagógico na escola, tendo em vista a complexidade de tarefas administrativas e pedagógicas em prol do enfrentamento de determinadas demandas educacionais com os quais se deparam os gestores escolares.

Cada escola traz suas experiências existenciais distintas, que nos instiga aproximar as reflexões teóricas com as situações concretas. Há que favorecer as experiências inovadoras, contemplar este objetivo pedagógico, dentre outras providências que se tornem indispensáveis para o sucesso de uma formação em serviço, transformando a sua missão quanto ao atendimento às especificidades da qualidade educacional.

O conjunto de habilidades exigidas dos gestores escolares está cada vez maior, de modo a facilitar a introdução de mudanças na gestão, atribuídas a questões internas à vida escolar. Caracterizar as formas de pensar e agir na gestão escolar aponta para valorização da participação dos atores envolvidos no processo educativo. Se considerarmos a formação como um processo contínuo que acompanha, assiste e marca atitudes e capacidades que são exigidas ao gestor, a essas circunstâncias associam-se novas tendências e modificações no âmbito escolar, aos níveis pedagógicos, que precisam também passar por uma mudança profunda, procurando assegurar um padrão de qualidade que oriente o trabalho do gestor em exercício na escola.

Apresentar os avanços e os possíveis desafios que possam emergir para o melhor funcionamento do curso e, acima de tudo, para uma adequada formação continuada para aqueles que dela necessitam, constitui o desafio no tempo presente. Desenvolver nesse campo a tentativa de suprir as lacunas relativas à precariedade da educação escolar, no que diz respeito aos aspectos pedagógicos, marca os rumos dos programas formativos e ações educacionais desenvolvidas em cada escola, delimitando com mais clareza como temos conseguido atingir as expectativas do Programa Nacional Escola de Gestores da educação Básica do Ministério da Educação. Com esse feedback será possível inferir fenômenos educacionais listados por gestores, sujeitos que dialogam com a construção de realidades mais democráticas e qualitativas da rede pública de ensino.

\section{Considerações finaIS}

As discussões aqui explicitadas, que se referem a trabalho pedagógico escolar, formação de gestores escolares e educação a distância, são referenciais a partir dos 
quais seria possível ampliar um pouco mais o olhar para realidade a ser investigada no âmbito escolar.

A contribuição de pesquisa dessa natureza permite constatar se os participantes concluintes do programa estão se comprometendo com os objetivos de aprendizagem, atuação e transformação propostos pelo mesmo. E representa um meio pelo qual o cursista possa refletir sobre seu envolvimento nas atividades propostas e verificar se as estratégias educacionais realizadas têm sido adequadas para atingir os objetivos educacionais na gestão de sua escola.

Desafiado a sugerir e demonstrar algo que nunca experimentou, o docente pode conquistar credibilidade e veracidade aos resultados das discussões durante as atividades desenvolvidas, aproximar conteúdos do ensino a distância daquele desejado no âmbito da sua formação. A contribuição e uma pesquisa dessa natureza permitem constatar se os participantes concluintes estão se comprometendo com os objetivos de aprendizagem, atuação e transformação propostos na formação docente a distância e isso muitas vezes ocorre sem as devidas argumentações que estão postas por quem, de alguma forma, atende aos interesses oficiais, divulgados nos documentos de apresentação da proposta de ensino a distância, de fomentar a reflexão e a percepção dos sujeitos nele envolvidos.

Desse modo, o resultado a ser esperado acena para a forma como os docentes estabelecem conexões, identificam erros e apontam soluções, observam sistematicamente as ações e as reações, identificando lacunas e enlaces conceituais adquiridos ao longo de sua formação por meio do ambiente virtual de aprendizagem. Neste apelo ao protagonismo dos gestores reside também certa aspiração a tornar a educação a distância próxima e interativa, dando relevância às formas de abordagens que cada um descreve, seguindo o indicativo da proposta de formação por eles cursada e pela crença de que eles ainda não tiveram a oportunidade ou ainda não se posicionaram e que são capazes de relatar com propriedade o desenvolvimento do trabalho pedagógico escolar.

É preciso examinar situações que possibilitem a reflexão e a tomada de consciência das limitações sociais, pedagógicas e administrativas da escola e que se enquadrem na busca de eficiência e de influência sobre as atividades de ensino, que vão desde o processo de sistematização de objetivos à readequação da relação entre meios e fins, dando importância às melhorias notórias nas tarefas educativas com enfoque especial para o trabalho pedagógico na escola.

É nesse momento que podemos refletir sobre o que tem sido possível alcançar com determinadas experiências dada a bagagem teórica e metodológica de atuação pedagógica e administrativa que cada cursista possui ao longo de sua carreira profissional. Dessa forma, o resultado a ser esperado acena para a forma como os cursistas estabelecem conexões, identificam erros e apontam soluções, observam sistematicamente as ações e as reações no intuito de identificar erros, lacunas e soluções aos enlaces conceituais adquiridos ao longo de sua formação continuada do Programa Escola de Gestores da Educação Básica.

A preparação atual dos gestores ainda não é suficiente para superar os aspectos que têm impacto nos resultados pedagógicos e educacionais - estilo de gestão e de liderança, questões pessoais, experiências vividas, recursos físicos e materiais - e as políticas que têm oportunizado cursos de formação inicial e continuadas para gestores de escolas. É necessário buscar, democraticamente, o diálogo e a avaliação, em 
consonância com a rede de ensino, no intuito de ouvir professores e gestores sobre a proposta do governo, sendo os mesmos convidados a se pronunciar e a se envolver na definição de suas diretrizes e prioridades, permitindo uma definição mais adequada às políticas formativas e seu uso nos diferentes setores educacionais. Tais resultados podem ser tomados como puro reflexo da realidade escolar, bem como supõe uma possível melhoria no material didático utilizado nos cursos em EaD. Por isso as formas de abordagens pelos cursistas, no que tange à sua participação, são de se supor um embate que passa necessariamente pelas posições políticas como indicativo da proposta de formação por eles cursada.

Enfim, essas reflexões não se esgotam apenas na posse de informações acadêmicas. É preciso desvelar a reflexidade presente na experiência desses gestores frente ao trabalho pedagógico exercido no âmbito da escola, por entendermos que há uma especificidade de informações que possibilite responder o caminho por entre as dobras de algumas importantes teorias e que poderá ajudar a dar continuidade a uma significativa prática e construção de atitudes que concorram para a melhoria da qualidade educacional. Esperamos que as indicações que foram dadas ao longo do curso possam envolver a atuação concreta dos cursistas e que estes continuem sendo capazes de aplicar e usar o aprendido em situações reais de sua vida e de seu trabalho.

\section{REFERÊNCIAS}

ALONSO, Kátia Morosov. A avaliação e a avaliação na educação a distância: algumas notas para reflexão. In: ALMEIDA, Maria Elizabeth Bianconcini de, MORAN, José Manuel. Integração das tecnologias a distância. Brasília: Ministério da Educação, SEED, 2005. Disponível em: <http;//portal.mec.gov.br/seed/arquivos/pdf>. Acesso em: 11 maio 2015.

AZANHA, J. M. P. Uma reflexão sobre a formação do professor da escola básica. Educação e Pesquisa. São Paulo, v.30, n.2, p. 369-378, maio/ago. 2004.

AZZI, Sandra. Avaliação de desempenho do aluno na Ead. In: ALMEIDA, Maria Elizabeth Bianconcini de, MORAN, José Manuel. Integração das tecnologias a distância. Brasília: Ministério da Educação, SEED, 2005. Disponível em: <http://portal.mec.gov.br/seed/arquivos/pdf>. Acesso em: 11 de maio de 2015.

BRASIL. Presidência da República. Lei de Diretrizes e Bases da Educação Nacional - Lei no 9.394/1996. Brasília, DF, 1996. Estabelece as diretrizes e bases da educação nacional. Disponível em: <http://www.planalto.gov.br/ccivil_03/leis/l9394.htm>. Acesso em: 17 ago. 2013.

BRASIL. Presidência da República. Escola de gestores da Educação Básica. Brasília, DF, 2006. Disponível em: <http://portal.mec.gov.br/index.php?option=com_content\&view=article\&id=12337: $>$. Acesso em: 22 mar. 2013.

BRASIL. Presidência da República. Programa Nacional Escola de Gestores da Educação Básica Pública. Brasília, DF, 2005. Disponível em: <http://gestao2010.mec.gov.br/o_que_foi_feito/program_29.php>. Acesso em: 22 mar. 2013.

BELLONI, M. L. Tecnologia e formação de professores: Rumo a uma pedagogia pós-moderna? In: Educação e Sociedade, v. 19 o․ 65. Campinas: CEDES, 1998. Disponível em: <http://www.probe.br>. Acesso em: 02 fev. 2014.

CANDEIAS, C. N. B. Formação de professores, tecnologias da informação e comunicação e pós-graduação: uma possível articulação. Educação em perspectiva, v.4, n.2, jul./dez.2013, p. 372-390.

CURY, C. R. J. Gestão democrática da educação: exigências e desafios. Revista Brasileira de política e Administração da Educação, São Bernardo do Campo, v. 18, n. 2, p. 163-174, jul./dez, 2002. 
FELINTO, Maria Angélica de Souza; PEDREIRA, André Luiz Simões. A importância da formação continuada no desenvolvimento do trabalho dos gestores escolares e coordenadores pedagógicos no ambiente escolar, p. 225-254. In: ALVES, Iracy Maria de Azevedo; GÓES, Meire Conceição Leite (Orgs.). 0 coordenador pedagógico no contexto escolar, Salvador EDUFBA, 2014.

FREITAS, Kátia Siqueira de. Gestão Escolar, qualidade do ensino e políticas públicas. p. 6781. In: FRANÇA, Magna; BEZERRA, Maura Costa. Política educacional: gestão e qualidade do ensino - Brasília: Líber livro, 2009.

GATTI, Bernadete. Critérios de qualidade. In: ALMEIDA, Maria Elizabeth Bianconcini de, MORAN, José Manuel. Integração das tecnologias a distância. Brasília: Ministério da Educação, SEED, 2005. Disponível em: <http://portal.mec.gov.br/seed/arquivos/pdf>. Acesso em: 11 de maio de 2015

GATTI, Bernadete. Análise das políticas públicas para formação continuada no Brasil, na última década. Revista Brasileira de Educação, V.13, n. 37, jan/abr. 2008. Disponível em: <http://www.scielo.br/pdf/rbedu/v13n37/06.pdf>. Acesso em: 24 mai. 2014.

LÜCK, H. Perspectivas da Gestão Escolar e Implicações quanto à Formação de seus Gestores. Em aberto, Brasília, v. 17, n. 72, p. 11-33, fev./jun. 2000.

MILL, Daniel. Docência virtual: uma visão crítica. SP: Papirus, 2012.

NEVES, Carmem Moreira de Castro. A educação a distância e a formação de professores. In: ALMEIDA, Maria Elizabeth Bianconcini de, MORAN, José Manuel. Integração das tecnologias a distância. Brasília: Ministério da Educação, SEED, 2005. Disponível em: $<$ http://portal.mec.gov.br/seed/arquivos/pdf>. Acesso em: 11 de maio de 2015.

PEREIRA, Marilza Aparecida Pereira. Formação para diretor escolar da educação básica: o programa Nacional Escola de Gestores no estado do Paraná. Dissertação (mestrado). Universidade Federal do Paraná. Curitiba, 2011, 135 f.

QUEIROZ, Maria Aparecida de; GADELHA, Maria José de A. Formação de Gestores Escolares a distância: avaliação do ensino. Disponível em: <http://www.anpae.org.br/iberoamericano2012/Trabalhos/MariaAparecidaDeQueiroz_res_int_GT2.pdf>. Acesso em: 24 mai. 2014.

RIVAS, N. P.P.; PEDROSO, C. C. A. P.; LEAL, M.A.I.; CAPELINI, H. A. A (re) significação do trabalho docente no espaço escolar: currículo e formação. VIII Congresso Estadual Paulista sobre Formação de Educadores, UNESP - Universidade Estadual Paulista, 2005. Disponível em: <http://www.unesp.br/prograd/e-book\%20viii\%20cepfe/LinksArquivos/9eixo.pdf>. Acesso em: 26 de maio de 2014.

SEVERINO, A. J. A formação e a prática do professor em face da crise atual dos paradigmas educacionais. Ciência \& Opinião, v. 1, n. 2/4, p. 15-31, 2004.

TEIXEIRA, Marilza Aparecida Pereira. Formação para diretor escolar da educação básica: 0 programa Nacional Escola de Gestores no estado do Paraná. Dissertação (mestrado). Universidade Federal do Paraná. Curitiba, 2011, 135 f.

TORRES, R. M. Educação para Todos: a tarefa por fazer. Porto Alegre, Artes Médicas, 2001, A Resposta, p. 25-61.

Data da submissão: 04/12/2018

Data da aprovação: 21/02/2019 